Article

\title{
Journalism in Digital Native Media: Beyond Technological Determinism
}

\author{
Berta García-Orosa *, Xosé López-García and Jorge Vázquez-Herrero \\ Communication Sciences, Universidade de Santiago de Compostela, 15782 Santiago de Compostela, Spain; \\ E-Mails: berta.garcia@usc.es (B.G.-O.),xose.lopez.garcia@usc.es (X.L.-G.), jorge.vazquez@usc.es (J.V.-H.) \\ * Corresponding author
}

Submitted: 12 December 2019 | Accepted: 1 February 2020 | Published: 16 April 2020

\begin{abstract}
This article reflects on the conceptualisation and practise of journalism in European digital native media. The way news is produced and consumed in the digital era knocks down the boundaries that once divided professionals, citizens, and activists. At the same time, significant changes highlighted in recent studies call for a new theoretical and practical approach that goes beyond the dominant perspective of technological determinism. In relation with previous research, we have selected innovative digital media platforms (De Correspondent, Heidi.news, Eldiario.es, IIPost, Mediapart, and Observador), and we have analysed the types of journalism they set out to produce, as gleaned from their public-facing communications and interviews with the platforms' founders and editors, comparing their stated goals with the journalism they produce and, lastly, we commented on changes in journalism. Digital native media explore renewed fields for journalism. The present analysis allows identifying the emergence of a series of trends in digital native media, which show a coexistence of traditional and new principles. Beyond the technological impact, the new media respond to the needs of society by incorporating the citizen as a reason for its purpose and as a collaborator in production processes. On the other hand, new players and an updated role of journalists come into play with innovative proposals designed for the current multiplatform and mobile scenario.
\end{abstract}

\section{Keywords}

digital journalism; digital native media; innovation; journalism; social media

\section{Issue}

This article is part of the issue "Digital Native News Media: Trends and Challenges" edited by Ramón Salaverría (University of Navarra, Spain).

(C) 2020 by the authors; licensee Cogitatio (Lisbon, Portugal). This article is licensed under a Creative Commons Attribution 4.0 International License (CC BY).

\section{Introduction and Theoretical Framework}

The shaping of the network society as a new structure in which morphology is over action (Castells, 1996), within a social scenario characterised by modern liquidity (Bauman, 2000), has fuelled a complex ecosystem where media and humans interact (Postman, 2000), which should be also framed within an ever-changing environment. There is where digital native media emerge, showing more or less balanced features of hybridisation between the older media logics, broadcasting and reception, and the new logics of circulation and negotiation (Chadwick, 2013). This scenario of changes calls for a review of digital journalism in native media, as it must face renewed challenges using audacious formulas, with the aim of fulfilling its tasks in the new social, political, and economic context of the network society (Zelizer, 2017).

To address this challenge, we must overcome approaches that, for digital journalism, only contemplate the old referential frameworks and study models of content production (Mitchelstein \& Boczkowski, 2009), and those who point to technological determinism in journalism (Örnebring, 2010) as a cause of the changes that have taken place and those that are underway in journalism, both in professional practices and in all journalistic dimensions (Singer, 2018). It is therefore necessary to place the study of digital native media-and the journalism they practice-within the framework of diversity and interdisciplinary nature of journalism studies and in the setting of their conceptual debates (Steensen, Grøndahl 
Larsen, Hågvar, \& Fonn, 2019). Data over the last 25 years show that research on digital journalism is a consolidated and developing discipline, although with relevant methodological and thematic challenges to face in the coming years (Salaverría, 2019).

The steps to move forward and face the challenges must necessarily contemplate that the way in which news is produced and consumed in the digital age has broken down old boundaries between professionals, citizens, and activists and has created a new scenario in production, information uses, and consumption, redefining limits and roles in communication processes and news production (Carlson \& Lewis, 2015; Linaa Jensen, Mortensen, \& Ørmen, 2016; Witschge, Anderson, Domingo, \& Hermida, 2016). Changes in the environment and in the profession did not leave professionals unmoved, as they maintained resistance to changes in working cultures (Ryfe, 2012). Transformations in the journalistic field did not prevent many journalists committed to traditional standards to be expelled from the profession (Usher, 2010), also due to the emergence of a new panorama characterised by the hybridisation of practices (Hamilton, 2016), the ways in which information is produced and disseminated (Domingo, 2016), and the search for new narratives (Gander, 1999; Jenkins, 2003; Scolari, 2014; Shin \& Biocca, 2018). Although there is still no consensus on the conceptualisation of a new language (Castro, Pérez, \& Amatta, 2016), the truth is that the language of journalism is becoming more and more multichannel, polysynthetic, and integrative (Vulchanova, Baggio, Cangelosi, \& Smith, 2017), within a narrative with hyper-fragmented textualities and a variety of players involved in the production of the message (Adami, 2017).

Many reports such as the Digital News Report 2019 from the Reuters Institute (Newman, Fletcher, Kalogeropoulos, \& Nielsen, 2019) and The Impact of Digital Platforms on News and Journalistic Content from the Centre for Media Transition (Wilding, Fray, Molitorisz, \& McKewon, 2018), among others, have revealed the changes in news production and the operation of digital media, especially since the popularisation of social networks and their impact on news production (Ferrucci, 2018). From 2010 onwards, the search for ways to conquer the future of journalism has become a path of risks, threats, and opportunities (Franklin, 2016).

The search for renewed ways has driven the processes of journalistic innovation (Paulussen, 2016) and has given prominence to the application of journalistic values with good strategies for user participation (Hujanen, 2016), to the emotional burden of information (Beckett \& Deuze, 2016), and to the empathy between journalists and users (Glück, 2016). Although the absence of technological determinism is recognised, journalism explores new skills and dimensions (Pavlik, 2019) due to the impact of technology. The rise of social networks and their effect on mediated communication in present societies, as well as mobile communication, ar- tificial intelligence, virtual reality, and transmedia strategies, have encouraged the search for experimental and innovative responses. Considering this context, the new media scenario shows conditions for quality digital journalism, which meets the highest ethical standards. In fact, from the conviction that the future of journalism is in the network (van der Haak, Parks, \& Castells, 2012), many of the currently-existing experiences, both digital native and migrant, show that there are ways to ensure the future of journalism (Deuze, 2017).

These current digital media-meaning those that make up an alternative to the traditional media ecosystem, which innovate, use narrative formats, and have a new relationship with the audience (Cabrera Méndez, Codina, \& Salaverría Aliaga, 2019)-build the future of journalism and walk under the shadow of mobile communication for perpetual contact, which encourages extensions of the person for services, personalisation of content, and a updated meaning of place and time (Vanden Abeele, de Wolf, \& Ling, 2018). Production, dissemination, and consumption, as well as management, must be placed in this new ubiquitous scenario. The mobility paradigm establishes new dynamics and strategies aimed at intervention in production and consumption (Bui \& Moran, 2019), which offers as a result another possible journalism.

Current online media keep distinctive features since their birth, such as digitisation, multimedia, hypertextuality, interactivity, automation, and speed (Chung, 2007; Dahlgren, 1996; Deuze, 2004), but it should be placed within a changing environment like the current one, with traditional and alternative media (Holt, Ustad Figenschou, \& Frischlich, 2019) and renewed journalistic practices (Witschge, Deuze, \& Willemsen, 2019) offered by the contemporary digital network society.

\section{Method}

The main goal of this article is to identify new conceptualisations and ways of understanding journalism through a pragmatic analysis of 6 highlighted digital native media. The analysis paves the way for the development of new ways to investigate and teach journalism, by answering the following research questions:

RQ1. Do the analysed digital native media redefine journalism as a new social actor in their foundational documents?

RQ2. Do they include the citizen in the definition of journalism and in all production phases?

RQ3. Do digital native media still depend on institutional sources?

RQ4. Could it be confirmed an effective change in the conceptualisation of journalism or an occasional use of new strategies, supports and narratives? 
Table 1. Content analysis guidelines for the sample of news.

\begin{tabular}{lll}
\hline Identification & Topics & Sources \\
\hline Title & Main subject (section): & Use of sources (presence and volume): \\
News organisation & - Business & - Offline \\
URL & - Climate \& environment & - Digital and 2.0 \\
Date & - Integration of social media in production \\
& - Health & \\
& - International & Classification: \\
& - Politics (international) & - Government, public institutions \\
& - Science \& tech. & - Politics \\
& - Society & - Experts \\
& - Sports & - Media \\
& Various & - Journalist \\
& Secondary subject (specific topic) & - Civil society \\
& Immediacy & \\
\hline
\end{tabular}

The method has been designed ad hoc for this research. The selection of a mixed design allowed for the planning of three research methods. The first one seeks to know the self-definition of journalism raised by the analysed media. A review of online documents containing their mission and principles was carried out and, in addition, the founding members and directors of the media were contacted to find out how they apply their proposals, and also to evaluate the potential change in the journalism they exercise. Interviews were conducted in November 2019 to the following media: Observador (Miguel Pinheiro, director), Heidi.news (Serge Michel, director and co-founder), and II Post (Luca Sofri, director and founder), while De Correspondent (Rob Wijnberg, Carmen Schaak) provided a series of documents that were also analysed.

In order to examine whether there are changes in the practices of journalism towards an alternative journalism, a content analysis (Table 1) was prepared with the two most outstanding news of the homepage, based on a sample taken in alternate days during two weeks (12-25 October) to rebuild a full week.

Third, a follow-up of the selected media (Table 2) and an exploratory study were carried out to detect its char- acterisation in terms of organisation of the media, business model, and used formats, as well as the presence of mechanisms and strategies linked to participation, the use of social networks, and mobile communication.

\subsection{Media Selection}

De Correspondent was founded in the Netherlands by Rob Wijnberg and launched in September 2013 after a crowdfunding campaign in which they raised more than one million euros in 8 days. It currently has more than 60,000 members and has initiated the launch of the English portal The Correspondent, after achieving a collection of 2.6 million dollars in 29 days-and 45,888 members from 130 countries. It is a highlighted case concerning the Netherlands in the Digital News Report (Newman et al., 2019).

Eldiario.es was born in Spain as an initiative of a group of journalists led by Ignacio Escolar in September 2012. It has more than 34,000 members and it is managed through a society where more than $70 \%$ belongs to newsroom's workers. It is the journalistic digital native media most consumed in Spain, according to the Digital News Report (Newman et al., 2019).

Table 2. Exploratory study guidelines for the news media.

\begin{tabular}{ll}
\hline Category & Characterisation \\
\hline Organisation & Structure of contents \\
& Thematic specialisation \\
& Business model \\
Social media & Use of social networking sites in circulation \\
Participation & Mechanisms and strategies to enhance audience contribution \\
Formats and technology & Mobile communication \\
& Automation \\
& Multimedia, interactive and immersive formats \\
\hline
\end{tabular}


Heidi.news was launched in May 2019 in Geneve, headed by Tibère Adler and Serge Michel. The project was started with a million Swiss francs from ten founders and investors. A campaign of previous subscription allowed to reach 2,000 founding members. It is a prominent case in the Swiss context, as it became a new player supported by Google's Digital News Innovation Fund (Newman et al., 2019).

Il Post was born in April 2010 in Italy as a news aggregator project with its own content and directed by Luca Sofri. It is the journalistic digital native media most consumed in Italy, according to the Digital News Report (Newman, Fletcher, Levy, \& Nielsen, 2016; Newman, Fletcher, Kalogeropoulos, Levy, \& Nielsen, 2017).

Mediapart began its history in March 2008 in France, being Edwy Plenel president and director. It was originally created based on partnership-with a total initial investment of 2.9 million euros-but in July 2019 all the shares were sold to a non-profit fund for perpetual independent management. It is the journalistic digital native media most consumed in France, according to the Digital News Report (Newman et al., 2019).

Observador was born in Portugal in May 2014. José Manuel Fernandes is the editor and Miguel Pinheiro is the executive director. A group of investors took part in its foundation, being Luís Amaral the main shareholder. It is the first digital native media most consumed in Portugal (Newman et al., 2019).

\section{Results}

The following section summarises the main research findings. The structure is divided into two main sections. The first one, the foundational principles, exposes the vision, mission, and conceptualisation of journalism from the point of view of the different analysed media. To do so, corporate reports, previous statements of their managers, and interviews carried out for this article were used.

Second, the features of journalism performed by digital native media are analysed. For this purpose, the production process is divided into two phases: (a) production-two elements of journalism are highlighted in the analysis (sources and topics) and organisation; and (b) circulation-audience participation, formats, and platforms - although, in practice, borders are liquid. Finally, the role that journalism assumes in the new proposals is valued.

\subsection{Foundational Principles}

The analysed media build their projects from traditional journalistic foundations, with renewed practices and giving a high value to the reader, citizen, or user. Their differentiating factors, as far as principles are concerned, are related to the connection with society through participatory proposals and generation of communities, as well as in the interest in responding to the current con- text with a conception of innovative and constructiveor solutions-journalism. Categories shown in Table 3 were emerging open-coded themes based on the qualitative research, so after an overview of all statements and principles, we classified them into the categories there presented.

The integration of citizens into the environment implies enabling, favouring, and encouraging the participation and contribution of users, especially those experts in each area. In De Correspondent, all interventions in public discussions must be labelled with the authority that supports the participant's knowledge and experience: "We see readers as potential sources of expertise, who can enrich our journalism by actively sharing their knowledge and experiences" (Wijnberg, 2018a). On the other hand, the participatory approach seeks to build a conscious and involved public, as well as an intervening public opinion, as Mediapart and Observador state. The objectives of the Portuguese media include to explain the most complex issues of society for citizens to make better decisions (Pinheiro, personal communication, November 13, 2019). Organisations and individuals collaborate in common spaces that seek, on the one hand, to offer an alternative and differentiating journalistic proposal and, on the other hand, to be part of a community committed to what happens in society.

In this sense, analysed media express their intention to place the needs of the reader at the centre of their motivations and to provide useful information, as in the case of Heidinews, focused on health and science topics from a Swiss perspective and for an "amazingly competent" audience (Michel, personal communication, November 15, 2019). The agenda-setting is essential to fulfil this purpose of reconnecting with society (Eldiario.es), as well as to identify the problems and needs of citizens to respond to them (De Correspondent): "News that helps us make the world a better place" (Wijnberg, 2018b). Again, these are principles closely connected to the participatory nature of the project, both for the opening of new research lines based on user contributions and for building a relationship of trust and loyalty. In the case of De Correspondent and Heidi.news, they define in their principles the practice of a constructive journalism, giving priority to information, exposing problems and providing possible solutions.

However, in addition to the participatory nature and social commitment of the analysed digital media, they include in their mission the management of circumstantial factors. Eldiario.es and Heidi.news propose a response to the excess of information in circulation, while verification-a value proposed due to the proliferation of fake news-expressly appears in the founding principles of Mediapart and Heidi.news, also stated by Luca Sofri (personal communication, November 19, 2019) in reference to // Post. In both cases, there are factors driven by the phenomenon of social networks, confirming that it is an opportunity for the distribution of information, but also a challenge that they try to face. The emergence of 
Table 3. Relation of principles manifested in digital native media.

\begin{tabular}{|c|c|c|c|c|c|c|}
\hline Founding principles & De Correspondent & Eldiario.es & II Post & Heidi.news & Mediapart & Observador \\
\hline $\begin{array}{l}\text { Connection with society to answer } \\
\text { citizens' needs }\end{array}$ & $\bullet$ & $\bullet$ & & $\bullet$ & $\bullet$ & \\
\hline $\begin{array}{l}\text { Participatory project and } \\
\text { community's value }\end{array}$ & $\bullet$ & & $\bullet$ & & $\bullet$ & $\bullet$ \\
\hline $\begin{array}{l}\text { Priority to information, detecting } \\
\text { problems and solutions }\end{array}$ & $\bullet$ & & & $\bullet$ & & $\bullet$ \\
\hline Subscription funding model & $\bullet$ & $\bullet$ & & $\bullet$ & $\bullet$ & \\
\hline Independence & $\bullet$ & $\bullet$ & & & $\bullet$ & $\bullet$ \\
\hline Transparency & $\bullet$ & $\bullet$ & & & & \\
\hline Truth and quality & & $\bullet$ & $\bullet$ & $\bullet$ & $\bullet$ & $\bullet$ \\
\hline Defence of social values & $\bullet$ & $\bullet$ & & & & $\bullet$ \\
\hline $\begin{array}{l}\text { Motivation to research and } \\
\text { monitor }\end{array}$ & $\bullet$ & $\bullet$ & & $\bullet$ & & \\
\hline Answer to information overload & & $\bullet$ & $\bullet$ & $\bullet$ & & \\
\hline Innovation & & & & & $\bullet$ & $\bullet$ \\
\hline $\begin{array}{l}\text { Defence of journalism and } \\
\text { the role of journalists }\end{array}$ & & & & $\bullet$ & $\bullet$ & \\
\hline
\end{tabular}

new challenges demands new answers, which some digital natives explicitly reflect in their statutes. Observador is committed to innovation as one of its founding principles, while Mediapart proposes the redesign and refoundation of the press.

Following a more traditional line, all analysed media advocate for transparency, research and the watchdog role, the defence of social values, as well as the respect for the truth and the offer of quality information. In the case of /I Post, the need for a journalism with those characteristics was the reason for undertaking the project, according to Sofri (personal communication, November 19, 2019). In the same vein, they promise to maintain their editorial independence in a generalized way. This condition is supported by its original commitment to a membership-based funding model, which offers autonomy over the advertisingbased model. De Correspondent declares itself completely free of advertising and sponsored content, while Mediapart is deliberately independent from advertising and audience results. It is, therefore, a sample of the original search for an alternative for the funding of journalism, more focused on a faithful and committed public. Finally, it is also important to mention the proposal to defend journalism and the role of the journalist, raised by Mediapart and Heidi.news, a timely principle at a time of lack of confidence in the news.

\subsection{Features of Digital Native Media}

\subsubsection{Production}

The analysed media, as noted by their foundational documents, look for innovation for presenting information, while paying special attention to the essence of journalism: audience-oriented contents and sources contrast.

In the first case, the contact with the receiver they seek to lead can help to transform topics and approaches towards meeting the needs of the audience. It is convenient to highlight, in this sense, the presence of national and international politics being $52.4 \%$ of the analysed information. This figure, however, must be weighed because of the distortion of the inclusion of Eldiario.es, since Spain was at that time in pre-election campaign and the political scenario covered almost all the information published on the days we collected the data. If Eldiario.es is excluded from the sample, $43.2 \%$ of political information is obtained. In total, $78.0 \%$ of the news responds to current events. However, De Correspondent stands out with $75.0 \%$ of analysed news that does not stick to it.

As shown in Figure 1, it is also remarkable the importance obtained by the topics of society (53.6\%) and, to a lesser extent, economy (1.2\%), that account for most of the media information analysed against what we could call traditional journalism. 


\section{COGITATIO}

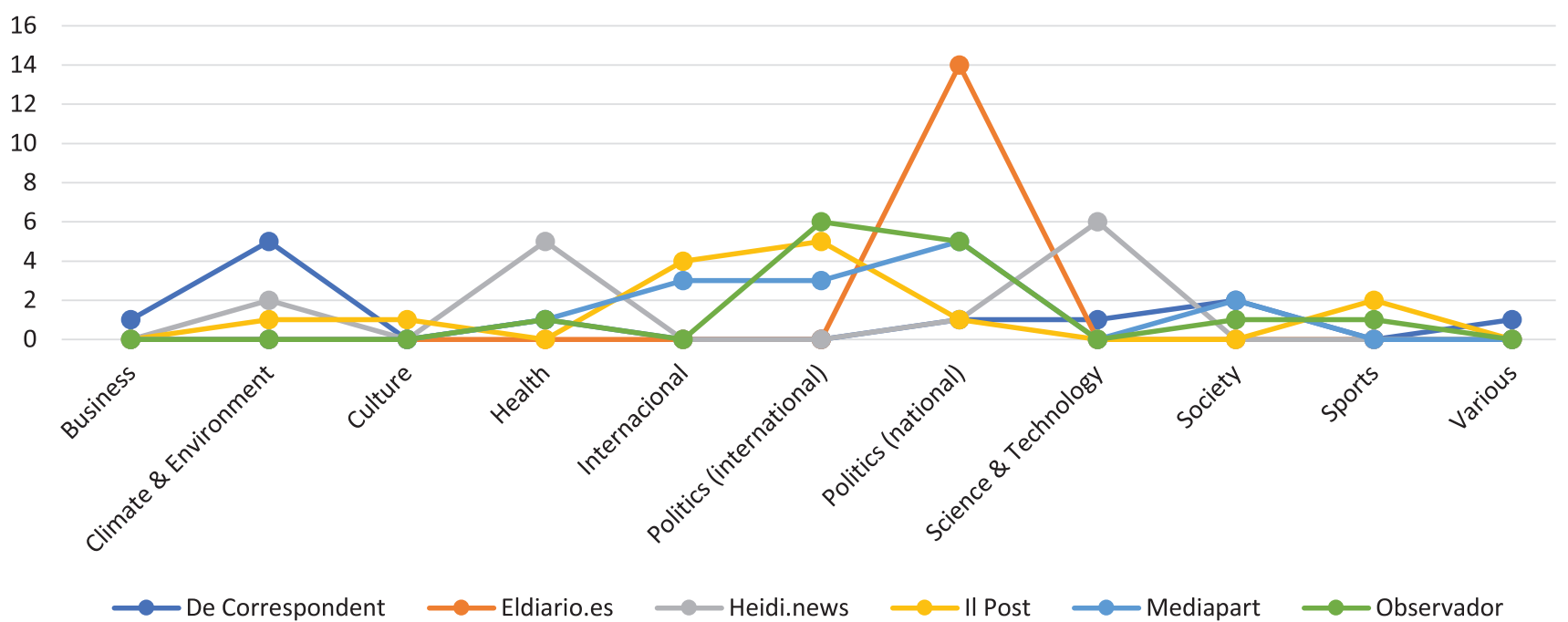

Figure 1. News classified by topics in analysed digital native media.

The shift in topics is accompanied by a change in the treatment of sources, as shown in Figure 2 (an average of 3.4 sources present per piece of news), and a broadening of the spectrum of the society reflected with the inclusion of citizens (present in $30.5 \%$ of the news), institutional sources (53.7\% government; $18.3 \%$ political parties; $8.5 \%$ private institutions), and experts (24.4\%). Regarding digital sources, $23.2 \%$ of the analysed news make use of them, mainly by inserting content from social networks such as Twitter and Facebook.

\subsubsection{Alternatives in Media Organisation}

In the selected cases, some strategies emerge and mark a break with the more conventional models in terms of structure, specialisation, and business. Faced with the usual proposal of a website organised by sections, topical, and broad thematic coverage, De Correspondent focuses on the figure of the 'correspondent' or journal- ist and collections. In this way, the Dutch media organises their stories based on the signature and thematic classifications, which correspond to contemporary universal debates, without a direct link to current news. In this way, the user can follow and prioritise the exposure to information of certain specialised authors -42 in October 2019, together with 446 invited signaturesand of specific approaches-such as the impact of artificial intelligence, euthanasia, climate emergency, etc. The proposal of thematic collections that the user can follow also appears in Mediapart ('Dossiers'), Heidi.news ('Les Explorations') and Observador (labels). On the other hand, the Swiss medium Heidi.news focuses on two issues relevant to its community-health and sciencearound which all its production revolves.

Regarding the business model, media based on advertising coexist with the support of members (Eldiario.es, II Post, and Observador) with projects based mainly on the contributions of its members

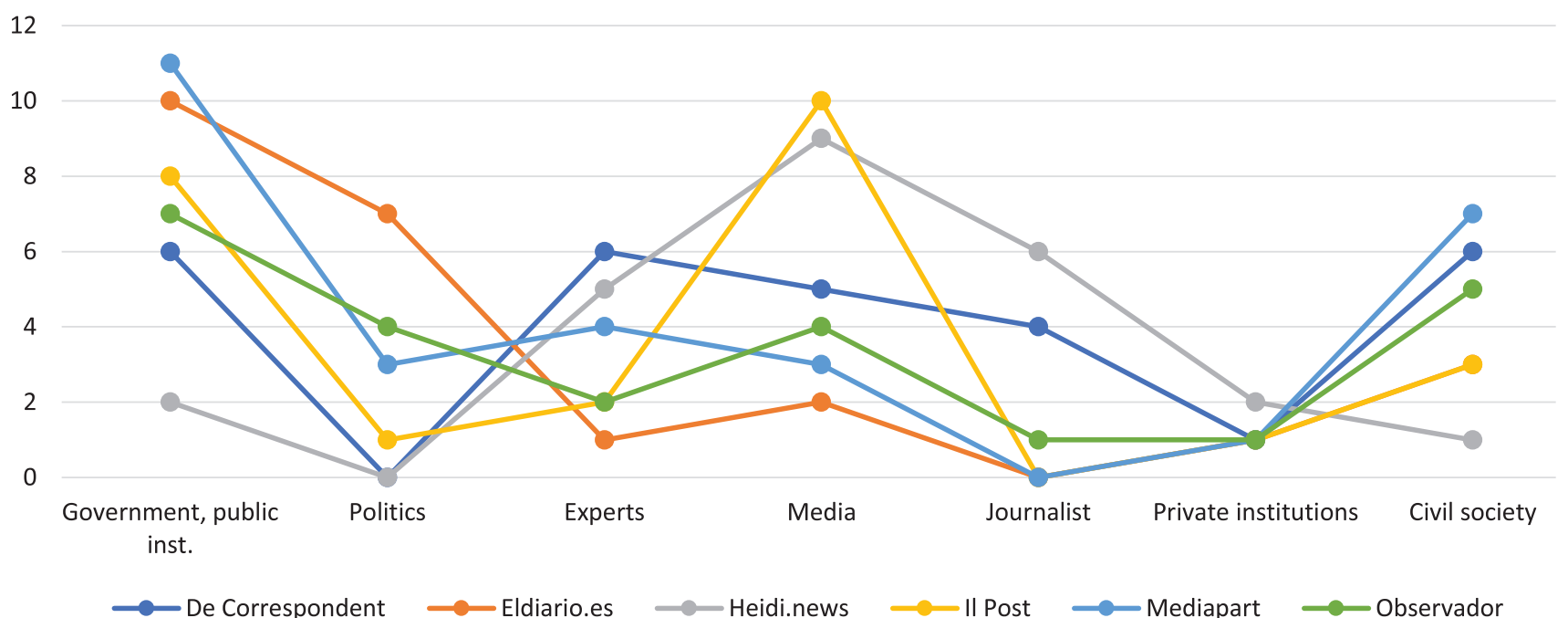

Figure 2. News classified by sources in analysed digital native media. 
(De Correspondent, Heidi.news, and Mediapart), being the membership in this last group a requirement for full access, newsletters, and participation.

\subsubsection{Integrating Participation in the Dynamics of the Media}

The participatory nature of the media is one of the most characteristic features in digital native media, from conservative proposals such as the contribution through comments-present in all the cases analysed except in Heidi.news - to the creation of communities and the promotion of conversation. The case of De Correspondent should be stressed out, where the conversation editor Gwen Martél is responsible for facilitating that the topics addressed are enriched with the knowledge and experience of readers, as well as to start new stories. In this way, a conversation arises from each article where members debate with journalists and experts. In other cases, participation is activated through direct contact with the authors through email as in Observador or Heidi.news, or a specific space as in 'Eldiario.es responde,' where Ignacio Escolar answers the questions of readers on a weekly basis. Observador also opens channels for users' participation in interviews and reports, to send questions, suggest perspectives, or tell their stories (Pinheiro, personal communication, November 13, 2019).

Another of the emerging initiatives to connect with the public and society is the celebration of thematic events, meetings with partners, debates, and presentations (Heidi.news, Eldiario.es, II Post, and Observador). In the case of the Italian media, they organise 'TALK' events, in addition to meetings with the director and journalists in different cities and the journalism course at the Scuola Belleville in Milan-a modality aimed at training and dissemination, as also developed by De Correspondent through the Correspondent College program. Observador organises the program 'Conversas' with guests and partner companies, fundamentally addressing social issues, volunteering, communities, and education. In Mediapart, the 'Mediapart Live' series is based on live discussions broadcast on the web from the newsroom.

However, to contribute to research and journalistic production, the media enable channels where users can give clues, make leaks, and suggest corrections. In the case of De Correspondent, Observador, and Heidi.news, contributions are directed to journalists; in Eldiario.es, through the PGP code, secure mailbox in Filtrala, and email; and in Mediapart, from the FrenchLeaks website, through web contact, email, postal mail, Tor address, or a mailbox.

Finally, the search for participation in digital natives is reflected in the commitment to create meeting spaces for its most loyal audience, its journalists, and other entities. Eldiario.es hosts blogs from different organisations and social groups to create a space for plural debate with common values, and II Post has numerous journalists' blogs and a blog of the news company itself. However, some projects stand out because of their community value and their participatory proposal: Mediapart places 'Le Club' section as a central aspect, where subscribers' blogs are located. These spaces show intense activity and are present on the homepage of the medium, through the recommendation of other subscribers and the newsroom. In addition, they allow to create a 'participatory edition' on a topic, create portfolios with photos, or add events to the media agenda.

\subsubsection{Formats and Platforms to Make Journalism}

The media analysed have adopted multimedia hypertextual creation in a natural way, especially with regard to the combination of text with images and video, as well as the interconnection of documents. However, there are some outstanding strategies in terms of how to present the information that give rise to trends. II Post is committed to brief contents in the 'flashes' and 'bits' sections, while Observador creates a type of article called 'explainer' that answers the big questions surrounding current events to build a context that can be addressed by any reader. Multimedia specials are a relevant format in the innovation of Eldiario.es, with significant cases such as 'Las Llaves de Europa' or 'Detrás del paraíso.' On the other hand, the French media Mediapart is committed to different multimedia formats that provide visual character, such as 'panoramique,' 'les documentaires,' and 'les portfolios.'

One of the most important trends worldwide and also in digital natives is the revaluation of audio formats, from the stories read in De Correspondent to podcasts in the same medium and in Eldiario.es, II Post, Mediapart and Observador - the latter also integrates its own radio, Rádio Observador. The sections dedicated to information verification, in response to the proliferation of fake news, are also reflected in these media: El Detector from Eldiario.es and Maldita.es, FrenchLeaks from Mediapart, and Fact Check from Observador.

Among the paths explored by digital native media is the edition of thematic books (De Correspondent) and monographic magazines (Eldiario.es), as well as the production of documentaries in collaboration with other media (De Brug, co-produced by De Correspondent and $K R O-N C R V)$. The search for a new revenue stream drives the opening of branded content lines. This is identified in ED Creativo of Eldiario.es and in Observador Lab from Observador.

As regards channels and platforms for distribution, the mobile device is a key element with different strategies. On the one hand, the analysed digital natives opt for their own application for these devices, while De Correspondent and Heidi.news prefer to maintain a responsive website that facilitates consumption on mobile phones and tablets as well. Social networks are spaces where all digital media take positions, especially on Twitter, Instagram, and Facebook, but also in other digital services where they give access to their content: 
YouTube, Soundcloud, Medium, LinkedIn, Tumblr, and Pinterest. In the case of II Post, it has also explored smart speakers, while Observador has an app for smartwatch. Instant messaging applications are used by Eldiario.es and Observador to spread their news.

However, all the media analysed give a relevant presence to newsletters with different focus and frequency of publication. The most common is the daily or weekly news summary, but there are also thematic examples like 'Les flux' from Heidi.news on science and health.

\subsubsection{Do Journalism and the Role of Journalists Change?}

Is there a transformation in journalism and the role of journalists? The overall response is a negative one: "The role of journalists remains the same: asking difficult questions and explaining complex topics" (Pinheiro, personal communication, November 13, 2019); "The role of the journalist is unchanged: looking for the truth....He's a humble craftsman" (Michel, personal communication, November 15, 2019). However, the proposals of some media do imply a shift in the approach, due to circumstantial needs or by definition. In the case of /I Post, its small newsroom implies that all journalists have to know how to do everything (Sofri, personal communication, November 19, 2019). On the other hand, in the De Correspondent, the mission of 'unbreaking the news' involves a change as regards what news are, how are they produced, and how we pay for them.

The journalistic role is more a relationship than a property (Carlson, 2017), so it is being transformed, voluntarily or required by the context, and based on the same foundational principles of journalism through alternative ways of executing it, considering the communities, participation, and the need for a constructive or solutions journalism. Challenges faced by the analysed digital native media have to do with over-information, offering distinctive information (Pinheiro, personal communication, November 13, 2019) and adjusting to the availability of the audience (Michel, personal communication, November 15, 2019). However, challenges are very diverse in each case: They will look for growth (Heidi.news), the consolidation of a multimedia newsroom (Observador), and the success of an English version for the world (De Correspondent).

\section{Conclusion}

Digital native media emerge to respond to needs of various kinds-in the market, in society, and in the models of journalism-and they are created by experienced journalists with a career in legacy media. In this sense, projects have a degree of innovation that make them different and, beyond the force exerted by technology, they offer renewed approaches that coexist with the foundational principles of journalism. The main difference of these news digital native media-De Correspondent, Heidi.news, Eldiario.es,
Il Post, Mediapart, and Observador-is in the value they give to their community, through participatory strategies and thematic specialisation. In other words, they propose an even more audience-centric approach to journalism, in different degrees of development according to each organisation.

The journalist and the media do not pretend to be players of society and politics but, rather, continue to seek to be a filter in an increasingly complex society. Some of them refer directly to 'constructive journalism' that exposes problems and provides solutions to allow their audience to make good decisions. However, the limits of their work are liquid and permeable to society. Changes in the approach of journalistic projects progressively incorporate participatory dimensions, in terms of community and conversation-notably in The Correspondent and Mediapart-and present transformations that affect the perception of the updated role of journalists (Berganza, Lavín, \& Piñeiro-Naval, 2017; Carlson, 2017; Mellado, Márquez-Ramírez, Mick, Oller Alonso, \& Olivera, 2017; Weaver \& Willnat, 2012). They claim for the essence of journalism from which some media have moved away: topics that interest the audiencegreat debates and thematic specialisation, although with a subtle change of news values (in many cases, loss of the immediacy)-and a special care to sources and the contrast between them.

The hybridisation of logics of production and circulation mark a double flow: (a) towards the essence of journalism; and (b) towards the incorporation of new players and roles. In the latter, and closely related to the audience-centric approach, citizens access the media in all phases of production and circulation of information, usually identified as expert sources, of justified and proven relevance. Hybrid actions are also implemented in the production and circulation of information by combining online and offline actions (virtual communities, meetings, and debates with sources). Finally, formats and technical innovations are adapted to circumstances, especially in reference to the mobile and the use of newsletters for distribution, while automation, immersive narratives, and transmedia strategies still stand out as emerging and underused techniques. As for the business model, they are based primarily on subscriptions and memberships, which will require a great differentiation to react to the symptoms of exhaustion of this model (Newman et al., 2019).

In general terms, 'alternative' has become a brand image throughout the media, despite having been unable to change the field of journalism itself (Bourdieu, 2000), which depends not only on the underlying technological apparatus but also on a complex structural framework in which some outstanding digital native media are significantly incorporating participation, as tested in this study. The so-called 'constructive journalism' or 'solutions journalism' (Aitamurto \& Varma, 2018; Mclntyre, 2019 ) is spreading around the globe and also demanding more attention from the conceptual and the critical 
perspective (Mast, Coesemans, \& Temmerman, 2019), although this is not new (Bro, 2019). The perspective of digital journalism from technological determinism passes above the journalistic values and practices that persist, as we have mentioned here. Journalism is more than technology (Zelizer, 2019), so it is important to consider technology as a driver or even a trigger for some purposes, but there are many edges to explore. Although journalism, once a static communicative process, has become a flow that includes media, journalists, sources, and audiences, one cannot infer from this alone a general change in its conceptualisation. As the field of digital journalism undergoes redefining changes (Eldridge, Hess, Tandoc Jr., \& Westlund, 2019), other types of journalism are arising in a phase that is gaining ground facing intelligent automation and in which a nascent $5 \mathrm{G}$ technology could drive changes in the production, dissemination, and consumption of news.

\section{Acknowledgments}

This article has been developed within the research project "Digital Native Media in Spain: Storytelling Formats and Mobile Strategy" (RTI2018-093346-B-C33) funded by the Ministry of Science, Innovation, and Universities and co-funded by the European Regional Development Fund (ERDF).

\section{Conflict of Interests}

The authors declare no conflict of interests.

\section{Supplementary Material}

Supplementary material for this article is available online in the format provided by the authors (unedited).

\section{References}

Adami, E. (2017). Multimodality. In O. García, N. Flores, \& M. Spotti (Eds.), The Oxford handbook of language and society (pp. 451-473). Oxford: Oxford University Press.

Aitamurto, T., \& Varma, A. (2018). The constructive role of journalism. Journalism Practice, 12(6), 695-713. https://doi.org/10.1080/17512786.2018.1473041

Bauman, Z. (2000). Liquid modernity. Cambridge: Polity Press.

Beckett, C., \& Deuze, M. (2016). On the role of emotion in the future of journalism. Social Media + Society, 2(3), 2056305116662395. http://doi.org/ $10.1177 / 2056305116662395$

Berganza, R., Lavín, E., \& Piñeiro-Naval, V. (2017). Spanish journalists' perception about their professional roles. Comunicar, XXV(51), 82-97. https://doi.org/ 10.3916/C51-2017-08

Bourdieu, P. (2000). Cuestiones de sociología [Sociology issues]. Madrid: Istmo.
Bro, P. (2019). Constructive journalism: Proponents, precedents, and principles. Journalism, 20(4), 504-519. https://doi.org/10.1177/1464884918770523

Bui, M. N., \& Moran, R. E. (2019). Making the 21st century mobile journalist: Examining definitions and conceptualizations of mobility and mobile journalism within journalism education. Digital Journalism, 8(1), 145-163. https://doi.org/10.1080/21670811. 2019.1664926

Cabrera Méndez, M., Codina, L., \& Salaverría Aliaga, R. (2019). What is new media? The views of 70 Hispanic experts. Revista Latina de Comunicación Social, 2019(74), 1506-1520.

Carlson, M. (2017). Journalistic authority: Legitimating news in the digital era. New York, NY: Columbia University Press.

Carlson, M., \& Lewis, S. C. (2015). Boundaries of journalism: Professionalism, practices and participation. New York, NY: Routledge.

Castells, M. (1996). The rise of the network society: Vol. 1 of the information age-Economy, society and culture. Oxford: Blackwell.

Castro, S., Pérez, L., \& Amatta, J. M. (2016). El enjambre digital en la política argentina: Twitter en las campañas 2011-2013-2015 [The digital swarm in Argentine politics: Twitter in the 20112013-2015 campaigns]. Rizoma, 4(1), 90-104. Retrieved from https://online.unisc.br/seer/index.php/ rizoma/article/view/6824

Chadwick, A. (2013). The hybrid media system: Politics and power. New York, NY: Oxford University Press.

Chung, D. S. (2007). Profits and perils: Online news producers' perceptions of interactivity and uses of interactive features. Convergence, 13(1), 43-61. https:// doi.org/10.1177/1354856507072856

Dahlgren, P. (1996). Media logic in cyberspace: Repositioning journalism and its publics. Javnost-The Public, 3(3), 59-72. https://doi.org/10.1080/13183222. 1996.11008632

Deuze, M. (2004). What is multimedia journalism? Journalism Studies, 5(2), 139-152. https://doi.org/ $10.1080 / 1461670042000211131$

Deuze, M. (2017). Considering a possible future for digital journalism. Revista Mediterránea de Comunicación, 8(1), 9-18. https://www.doi.org/10.14198/ MEDCOM2017.8.1.1

Domingo, D. (2016). News practices in the digital era. In T. Witschge, C. W. Anderson, D. Domingo, \& A. Hermida (Eds.), The SAGE handbook of digital journalism (pp. 145-147). London: SAGE.

Eldridge, S. A., II, Hess, K., Tandoc, E. C., Jr., \& Westlund, O. (2019). Navigating the scholarly terrain: Introducing the digital journalism studies compass. Digital Journalism, 7(3), 386-403. https://doi.org/10.1080/ 21670811.2019.1599724

Ferrucci, P. (2018). Networked: Social media's impact on news production in digital newsrooms. Newspaper Research Journal, 36(1), 6-17. 
Franklin, B. (2016). The future of journalism: Risk, threats and opportunities. Journalism Studies, 17(7), 798-800. https://doi.org/10.1080/1461670X. 2016.1197641

Gander, P. (1999). Two myths about immersion in new storytelling media. Unpublished manuscript. Retrieved from https://www.researchgate.net/ publication/228957892_Two_myths_about_ immersion_in_new_storytelling_media

Glück, A. (2016). What makes a good journalist? Empathy as a central resource in journalistic work practice. Journalism Studies, 17(7), 893-903. https://doi.org/ 10.1080/1461670X.2016.1175315

Hamilton, J. F. (2016). Hybrid news practices. In T. Witschge, C. W. Anderson, D. Domingo, \& A. Hermida (Eds.), The SAGE handbook of digital journalism (pp. 164-178). London: SAGE.

Holt, K., Ustad Figenschou, T., \& Frischlich, L. (2019). Key dimensions of alternative news media. Digital Journalism, 7(7), 860-869. https://doi.org/10.1080/ 21670811.2019.1625715

Hujanen, J. (2016). Participation and the blurring values of journalism. Journalism Studies, 17(7), 871-880. https://doi.org/10.1080/1461670X.2016.1171164

Jenkins, H. (2003). Transmedia storytelling: Moving characters from books to films to video games can make them stronger and more compelling. MIT Technology Review. Retrieved from https://www.technology review.com/s/401760/transmedia-storytelling

Linaa Jensen, J., Mortensen, M., \& Ørmen, J. (2016). News across media production: Production, distribution and consumption. New York, NY: Routledge.

Mast, J., Coesemans, R., \& Temmerman, M. (2019). Constructive journalism: Concepts, practices, and discourses. Journalism, 20(4), 492-503. https://doi.org/ $10.1177 / 1464884918770885$

McIntyre, K. (2019). Solutions journalism. Journalism Practice, 13(1), 16-34. https://doi.org/10.1080/ 17512786.2017.1409647

Mellado, C., Márquez-Ramírez, M., Mick, J., Oller Alonso, M., \& Olivera, D. (2017). Journalistic performance in Latin America: A comparative study of professional roles in news content. Journalism, 18(9), 1087-1106. https://doi.org/10.1177/1464884916657509

Mitchelstein, E., \& Boczkowski, P. J. (2009). Between tradition and change: A review of recent research on online news production. Journalism, 10(5), 562-586. https://doi.org/10.1177/1464884909106533

Newman, N., Fletcher, R., Kalogeropoulos, A., Levy, D. A. L., \& Nielsen, R. K. (2017). Digital news report 2017. Oxford: Reuters Institute for the Study of Journalism. Retrieved from http://www.digitalnewsreport. org/survey/2017

Newman, N., Fletcher, R., Kalogeropoulos, A., \& Nielsen, R. K. (2019). Digital news report 2019. Oxford: Reuters Institute for the Study of Journalism. Retrieved from https://reutersinstitute.politics.ox.ac. uk/risj-review/digital-news-report-2019-out-now
Newman, N., Fletcher, R., Levy, D. A. L., \& Nielsen, R. K. (2016). Digital news report 2016. Oxford: Reuters Institute for the Study of Journalism. Retrieved from https://reutersinstitute.politics.ox.ac. uk/our-research/digital-news-report-2016

Örnebring, H. (2010). Technology and journalism-aslabour: Historical perspectives. Journalism, 11(1), 57-74. https://doi.org/10.1177/1464884909350644

Paulussen, S. (2016). Innovation in the newsroom. In T. Witschge, C. W. Anderson, D. Domingo, \& A. Hermida (Eds.), The SAGE handbook of digital journalism (pp. 192-206). London: SAGE.

Pavlik, J. (2019). Advancing engaged scholarship in the media field. Media and Communication, 7(1), 114-116. https://doi.org/10.17645/mac.v7i1.1984

Postman, N. (2000). The humanism of media ecology. Proceedings of the Media Ecology Association, 1, 10-16. Retrieved from https://www.media-ecology. org/resources/Documents/Proceedings/v1/v1-02Postman.pdf

Ryfe, D. M. (2012). Can journalism survive? An inside look at American newsrooms. Cambridge: Polity Press.

Salaverría, R. (2019). Digital journalism: 25 years of research. El Profesional de la Información, 28(1), 1-27. Retrieved from https://recyt.fecyt.es/index.php/EPI/ article/view/epi.2019.ene.01

Scolari, C. (2014). Narrativas transmedia: Nuevas formas de comunicar en la era digital [Transmedia narratives: New ways of communicating in the digital age]. In J. Celaya (Ed.), Anuario AC/E de cultura digital (pp. 71-81). Madrid: Acción Cultural Española.

Shin, D., \& Biocca, F. (2018). Exploring immersive experience in journalism. New Media \& Society, 20(18), 2800-2823. https://doi.org/10.1177/ 1461444817733133

Singer, J. (2018). Transmission creep: Media effects theories and journalism studies in a digital era. Journalism Studies, 19(2), 209-226. https://doi.org/ 10.1080/1461670X.2016.1186498

Steensen, S., Grøndahl Larsen, A. M., Hågvar, Y. B., \& Fonn, B. K. (2019). What does digital journalism studies look like? Digital Journalism, 7(3), 320-342. https://doi.org/10.1080/21670811.2019.1581071

Usher, N. (2010). Goodbye to the news: How outof-work journalists asses enduring news values and the new media landscape. New Media \& Society, 12(6), 911-928. https://doi.org/10.1177/ 1461444809350899

van der Haak, B., Parks, M., \& Castells, M. (2012). The future of journalism: Networked journalism. International Journal of Communication, 6, 2923-2938.

Vanden Abeele, M., de Wolf, R., \& Ling, R. (2018). Mobile media and social space: How anytime, anyplace connectivity structures everyday life. Media and Communication, 6(2), 5-14. https://doi.org/10.17645/mac. v6i2.1399

Vulchanova, M., Baggio, G., Cangelosi, A., \& Smith, L. (2017). Editorial: Language development in the dig- 
ital age. Frontiers in Human Neuroscience, 11, 447. https://doi.org/10.3389/fnhum.2017.00447

Weaver, D. H., \& Willnat, L. (2012). The global journalist in the 21st century. New York, NY: Routledge.

Wijnberg, R. (2018a). The problem with real newsAnd what we can do about it. Medium. Retrieved from https://medium.com/de-correspondent/theproblem-with-real-news-and-what-we-can-doabout-it-f29aca95c2ea

Wijnberg, R. (2018b). Everyone is saying membership is the future of journalism: Here's how you can put it into practice. Medium. Retrieved from https://medium.com/de-correspondent/puttingmembership-into-practice-2e980c025fc9

Wilding, D., Fray, P., Molitorisz, S., \& McKewon, E. (2018).
The impact of digital platforms on news and journalistic content. Sydney: University of Technology Sydney.

Witschge, T., Anderson, C. W., Domingo, D., \& Hermida, A. (2016). The SAGE handbook of digital journalism. London: SAGE.

Witschge, T., Deuze, M., \& Willemsen, S. (2019). Creativity in (digital) journalism studies: Broadening our perspective on journalism practice. Digital Journalism, 7(7), 972-979. https://doi.org/10.1080/21670811. 2019.1609373

Zelizer, B. (2017). What journalism could be. Cambridge and Malden, MA: Polity Press.

Zelizer, B. (2019). Why journalism is about more than digital technology. Digital Journalism, 7(3), 343-350. https://doi.org/10.1080/21670811.2019.1571932

\section{About the Authors}

Berta García-Orosa is a Professor of Journalism at Universidade de Santiago de Compostela. She holds a degree in Journalism and in Political Science and Administration, also a PhD in Journalism. Her main research interests are digital media and organizational and political communication. Her latest publications include Language in Social Networks as a Communication Strategy: Public Administration, Political Parties and Civil Society and Algorithmic Communication and Political Parties: Automation of Production and Flow of Messages.

Xosé López-García is a Professor of Journalism at Universidade de Santiago de Compostela (USC), PhD in History and Journalism (USC). He coordinates the Novos Medios research group. His research lines are the study of digital and printed media, the analysis of the impact of technology in mediated communication, the analysis of the performance of cultural industries, and the combined strategy of printed and online products in the society of knowledge.

Jorge Vázquez-Herrero is a Lecturer and Researcher at Universidade de Santiago de Compostela (USC), PhD in Communication (USC). He is a member of Novos Medios research group and the Latin-American Chair of Transmedia Narratives (ICLA-UNR, Argentina). He was Visiting Scholar at Universidad Nacional de Rosario, Universidade do Minho, University of Leeds, and Tampere University. His research focuses on digital interactive narratives of non-fiction-mainly interactive documentary-micro-formats and transmedia, and immersive and interactive narratives in online media. 